\title{
Transcription factors that shape the mammalian pancreas
}

\author{
Rachel E. Jennings ${ }^{1,2}$ (D) $\cdot$ Raphael Scharfmann ${ }^{3}$ (D) $\cdot$ Willem Staels $s^{3,4,5}$ (D)
}

Received: 27 February 2020 / Accepted: 3 April 2020 / Published online: 31 August 2020

(C) The Author(s) 2020

\begin{abstract}
Improving our understanding of mammalian pancreas development is crucial for the development of more effective cellular therapies for diabetes. Most of what we know about mammalian pancreas development stems from mouse genetics. We have learnt that a unique set of transcription factors controls endocrine and exocrine cell differentiation. Transgenic mouse models have been instrumental in studying the function of these transcription factors. Mouse and human pancreas development are very similar in many respects, but the devil is in the detail. To unravel human pancreas development in greater detail, in vitro cellular models (including directed differentiation of stem cells, human beta cell lines and human pancreatic organoids) are used; however, in vivo validation of these results is still needed. The current best 'model' for studying human pancreas development are individuals with monogenic forms of diabetes. In this review, we discuss mammalian pancreas development, highlight some discrepancies between mouse and human, and discuss selected transcription factors that, when mutated, cause permanent neonatal diabetes.
\end{abstract}

Keywords Development $\cdot$ Human $\cdot$ Islets of Langerhans $\cdot$ Mouse $\cdot$ Neonatal diabetes $\cdot$ NEUROG3 $\cdot$ Neurogenin $3 \cdot$ Pancreas and duodenal homeobox $1 \cdot$ PDX $1 \cdot$ Regulatory factor X6 $\cdot$ Review $\cdot$ RFX6 $\cdot$ Transcription factors

$\begin{array}{ll}\text { Abbreviations } \\ \text { ABCC } 8 & \begin{array}{l}\text { ATP-binding cassette transporter subfamily C } \\ \text { member } 8\end{array} \\ \text { dpc } & \text { Days post conception } \\ \text { E } & \text { Embryonic day } \\ \text { GATA4 } & \text { GATA binding protein } 4 \\ \text { hPO } & \text { Human pancreatic organoid } \\ \text { hPSC } & \text { Human pluripotent stem cell } \\ \text { NEUROG3 } & \text { Neurogenin 3 } \\ \text { NKX6-1 } & \text { NK6 homeobox 1 } \\ \text { PDX1 } & \text { Pancreatic and duodenal homeobox 1 }\end{array}$

Electronic supplementary material The online version of this article (https://doi.org/10.1007/s00125-020-05161-0) contains a slide of the figure for download, which is available to authorised users.

Rachel E. Jennings

rachel.jennings@manchester.ac.uk

$\triangle$ Raphael Scharfmann raphael.scharfmann@inserm.fr

Willem Staels willem.staels@vub.be

1 Division of Diabetes, Endocrinology \& Gastroenterology, Faculty of Biology, Medicine \& Health, University of Manchester, AV Hill Building, Oxford Road, Manchester M13 9PT, UK
RFX6 Regulatory factor X6

SOX9 SRY-box transcription factor 9

wpc Weeks post conception

\section{Scope}

During human pancreas development, the orchestration of differentiation fates and the acquisition of endocrine and exocrine cell identity depend on the controlled expression of unique sets of transcription factors. Transgenic mouse models

2 Endocrinology Department, Manchester University NHS Foundation Trust, Manchester, UK

3 Institut Cochin, INSERM, U1016, CNRS, UMR8104, Université de Paris, 75014 Paris, France

4 Beta Cell Neogenesis (BENE), Vrije Universiteit Brussel, Laarbeeklaan 103, 1090 Brussels, Belgium

5 Department of Pediatrics, Division of Pediatric Endocrinology, University Hospital of Brussels, Jette, Belgium 
in which transcription factor expression can be manipulated have been key tools in studies to improve our understanding of pancreas organogenesis. Most of what we have learnt in mice holds true for humans, based on transcription factor expression patterns at different developmental stages. In this review we will discuss some of the differences that have been described. New tools have become available for refined experiments in which the expression of transcription factors can be modulated in human models. Stem cells, for example, have rapidly become a new paradigm for modelling organ development and disease. However, the gold standard for determining the impact of transcription factor perturbation on human pancreas development remains human gene allelic loss in individuals presenting with monogenic forms of diabetes. In this review we do not exhaustively list all transcription factors important for pancreas development, but we specifically address selected transcription factors during human pancreas development, the consequences of transcription factor perturbations on murine and human pancreas development, and neonatal diabetes as a means of understanding pancreas development. We also provide some reflections on therapy in developmental disorders of the pancreas.

\section{Human pancreas development}

Human pancreas specification is evident at $\sim 29$ days post conception (dpc), with detection of the transcription factor pancreas and duodenal homeobox 1 (PDX1) in the dorsal foregut endoderm, which is preceded by forkhead box protein A2 (FOXA2) expression at $27 \mathrm{dpc}$ [1]. In the mouse, PDX1 is detected slightly earlier, at embryonic day (E)8.5, which corresponds to $25-27 \mathrm{dpc}$ in humans [2]. By 30-33 dpc, both dorsal and ventral pancreatic buds are apparent, marked by the transcription factors PDX1, SRY-box transcription factor 9 (SOX9), GATA binding protein 4 (GATA4) and NK6 homeobox 1 (NKX6-1) [1]. At this point the buds contain multiple microlumens, which eventually form the luminal network of the branched pancreas. Both buds undergo a period of growth and branching, before fusing at 37-40 dpc [1]. During this time there is an expansion of multipotent progenitors, marked by the presence of SOX9, GATA4 and NKX61. In contrast with the mouse, there is no expression of the transcription factor NKX2-2 in the early human pancreatic buds $[1,2]$. With this exception, the early stages of human pancreas development follow a similar course to those in the mouse. In mice, the very first hormone-secreting cells appear at $\sim$ E9, shortly after pancreas specification ("primary transition'). These glucagon-expressing cells are transient and do not appear to contribute to the established endocrine cell population [2]. In contrast, there is no evidence of biphasic endocrine differentiation during human development. The first insulin-positive cells appear at 8 weeks post conception (wpc) [1]. This may reflect subtle anatomical differences between species; a lack of proximity of the paired dorsal aortae to the early pancreatic endoderm might prevent the pro-endocrine signals from the aortae that are observed in mouse [2]. The hallmark of endocrine differentiation in both mice and humans is the transient expression of the transcription factor neurogenin 3 (NEUROG3). In the mouse, NEUROG3 is first expressed at E9, heralding the primary transition. Its expression coincides with more prominent endocrine differentiation in the mouse at $\sim$ E13 ('secondary transition') [2]. In contrast, NEUROG3 is first apparent in the human pancreas at $8 \mathrm{wpc}$, expression peaks between 10 and $14 \mathrm{wpc}$ and then declines from $\sim 18 \mathrm{wpc}[1,3]$. It is not clear precisely when NEUROG3 is turned off in humans, but it is not detected by 35 wpc [3]. By transplanting human fetal pancreas into the mouse, NEUROG3 was detected in the graft until at least 19 weeks after transplantation [4]; both these findings suggest the period of endocrine differentiation is much longer in humans than in the mouse [5]. The downstream mechanisms by which NEUROG3 coordinates endocrine differentiation have been elucidated in the mouse [2, 6] and are overtly similar to those in humans. There are differences, such as the temporal expression of the transcription factors MafA and MafB; while MafB expression diminishes from beta cells postnatally in the mouse, its expression begins in human fetal pancreas and is sustained in adult beta cells [7, 8]. MafA expression in murine beta cells peaks soon after birth, whereas its expression continues to increase in juvenile and adult human beta cells [9, 10]. Thus, adult human beta cells express both MafA and MafB, while adult mouse beta cells only express MafA. For a comprehensive review on human pancreas development that also includes comparisons with mouse pancreas development, we refer the reader to [11].

\section{Transcription factors and mouse pancreas development: some outstanding questions}

The expression of several pancreas transcription factors has been experimentally modified by genetic perturbations in transgenic mice. The knowledge acquired from such manipulations justifies the considerable effort needed to generate these mice [2]. $P d x 1$, for example, has been extensively studied and its deletion in the mouse leads to pancreas agenesis $[12,13]$. This phenotype was first described almost 30 years ago but the underlying mechanisms by which loss of $P d x 1$ has these drastic consequences remain obscure. We know that the early events that induce pancreatic budding occur in these mice, and tissue recombination experiments suggest a cellautonomous defect in which pancreatic progenitor cells have lost competence to respond to morphogenic signals from the pancreatic mesenchyme [14]. However, we lack direct data demonstrating either decreased or absent proliferation or 
increased death of pancreatic progenitor cells in these mice. Neurog3 is another well-studied transcription factor, in part due to the dramatic phenotype of Neurog3-deficient mice, comprising a total lack of pancreatic endocrine cells, neonatal diabetes and early postnatal death [5]. Of particular interest is the contrast between the robust phenotype in Neurog3 null mice and the heterogenous presentation in people with NEUROG3 loss-of-function mutations, as described below. Finally, mice lacking $R f x 6$, encoding regulatory factor X6, a target of NEUROG3, fail to generate any of the pancreatic endocrine cells except pancreatic-polypeptide-producing cells and present with small bowel obstruction, pancreas hypoplasia, albeit inconstant, and early postnatal death [15]. Of interest in the case of RFX6 mutations in humans are the phenotypic differences compared with NEUROG3 mutations and the persistent role of RFX6 in adult beta cells.

\section{Models to study the role of transcription factors in human pancreas development}

Human model systems are preferable to animal models when studying human physiology and pathology to avoid the possibility of interspecies differences. However, studying the role of transcription factors in human pancreas development is more challenging because of a lack of appropriate models. In recent years, different in vitro models have been developed and used in studies aimed to increase our understanding of the impact of transcription factor perturbations on human pancreas development. First, the directed differentiation of human pluripotent stem cells (hPSCs) into pancreatic endocrine and exocrine cells has become a reliable model for normal cellular development and a valuable tool for studying pancreatic diseases (recently reviewed in [16]). For example, hPSCs have been used to study the function of specific transcription factors linked to neonatal diabetes. Either mutant cells from patients suffering from neonatal diabetes have been reprogrammed [17] or disease-specific mutations have been introduced into existing hPSC cell lines through genome editing techniques $[18,19]$. In addition, the human EndoC- $\beta \mathrm{H}$ beta cell lines have been used to study the impact on beta cell function of mutations in transcription factors found in patients with neonatal diabetes. Both gain-of-function studies using gene overexpression [20] and loss-of-function studies using siRNA-mediated knockdown [21] have been reported. Other envisioned strategies using this cell line include CRISPR/ Cas9 genome editing to mimic disease-specific mutations. While such 2D culture systems model cellular differentiation and are able to pinpoint developmental defects, they are, however, intrinsically unable to closely recapitulate organ growth, morphogenesis and the intercellular interactions between the endocrine and exocrine compartments. The development of human pancreatic organoids (hPOs) pushes cell culture methods into 3D and aims to more closely recapitulate in vivo differentiation. Organoids are defined as 3D structures grown from either hPSCs or tissue-resident stem/progenitor cells in which organ-specific cells spontaneously self-organise into differentiated functional cell types and at least some functions of the organ are recapitulated [22, 23]. A major advantage of hPOs is that they could be made from cells with disease-specific mutations. The closer mimicking of cellular interactions in a 3D culture of mouse pancreas progenitors has already been shown to more faithfully model exocrine and endocrine differentiation [24]. Methods for long-term culture of adult mouse pancreas organoids composed of $\mathrm{PDX}^{+}$ductal cells have also been established; however, endocrine differentiation was extremely limited in these 3D models [25]. For human cells, protocols for efficient expansion of fetal and adult duct-like tissue have been developed, however, again, subsequent differentiation into endocrine cells remains suboptimal $[26,27]$. While the abovedescribed models will surely increase knowledge on human pancreas development, caution remains warranted when interpreting these results as none of the models perfectly replicates in vivo pancreas development.

\section{Neonatal diabetes: a natural model to study the role of transcription factors in human pancreas development}

In the following paragraphs, we want to focus on how case reports or series of neonatal diabetes can be used to dissect the function of transcription factors during human pancreas development. Neonatal diabetes is a rare form of diabetes defined as diabetes diagnosed before 6 months of age (approximate incidence of 1:100,000 live births). Most babies with neonatal diabetes present with decreased birthweight (intra-uterine growth retardation due to fetal insulin deficiency), decreased fat reserves and low or undetectable C-peptide levels [28]. Neonatal diabetes could be classified according to the impact of its underlying mutation on aspects of pancreas development, from mutations causing complete pancreas agenesis, mutations that prevent islet formation, mutations that prevent beta cell development or cause early beta cell death, mutations that result in beta cells with defective insulin production or secretion, to mutations in the secreted insulin (Fig. 1). However, access to the pancreatic tissue of individuals with neonatal diabetes for post-mortem examination is very limited and in-depth studies of such pancreases are scarce. Somewhat over half $(\sim 57 \%)$ of affected babies have a transient, relapsing form of neonatal diabetes (TNDM) but in some of these cases diabetes may recur after a prolonged period [28, 29]. Currently, there is a list of 34 genes linked to permanent neonatal diabetes mellitus without autoimmune disease, which includes mutations in genes for 14 transcription factors, 


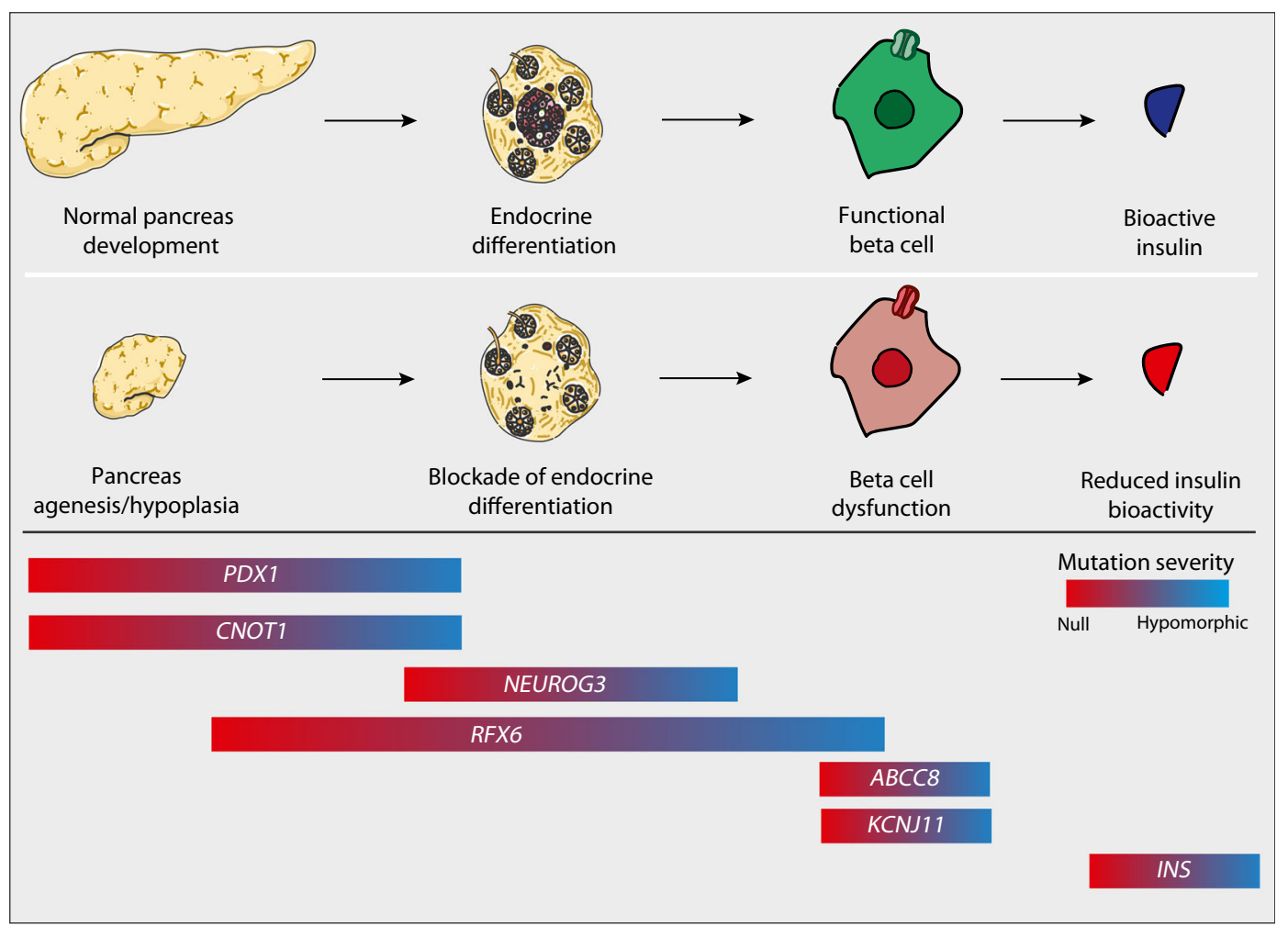

Fig. 1 Developmental classification of permanent neonatal diabetes. Transcription factors control normal human pancreas development, from its morphogenesis, through endocrine differentiation, to beta cell development and function. Mutations in transcription factor genes such as PDX1, NEUROG3 and RFX6 are responsible for different forms of permanent neonatal diabetes, thus, neonatal diabetes could be classified according to the developmental impact of the transcription factor mutations on pancreas, islet or beta cell formation. Mutations in genes that

insulin itself, genes encoding proteins needed for insulin secretion $(A B C C 8$ and $K C N J 11)$ and genes encoding proteins implicated in beta cell survival [30]. State-of-the-art genetic testing can find a genetic diagnosis for $82 \%$ of babies with neonatal diabetes [30]. In the last part of this review, we will specifically focus on permanent neonatal diabetes mellitus associated with mutations in three pancreatic transcription factors. These can be considered as human gene allelic loss models for studying the role of transcription factors in human pancreas development.

In 1997, Stoffers and colleagues first linked human pancreas agenesis to $P D X 1$ mutations [31] and, later, more studies confirmed this association $[32,33]$. Pancreatic agenesis results in a clinical phenotype of both endocrine and exocrine deficiency. The clinical presentation of mutations in pancreatic transcription factors can vary according to the severity of the mutations and, for $P D X 1$, cases presenting as isolated permanent neonatal diabetes mellitus without [34] or with subclinical exocrine insufficiency [35] have been reported. Interestingly, monoallelic loss of $P D X 1$ has a strong, negative impact on the generation of insulin-positive beta-like cells from hPSCs during in vitro differentiation $[18,36]$. This encode proteins involved in the machinery of insulin secretion ( $A B C C 8$, $K C N J 11)$ or insulin (INS) itself can also be included in such a developmental classification. Colour scale indicates mutation severity from null (red) to hypomorphic (blue). This figure was created using Servier Medical Art (https://smart.servier.com/). Servier Medical Art by Servier is licensed under a Creative Commons Attribution 3.0 Unported License. This figure is available as a downloadable slide

finding is intriguing as mice that are haploinsufficient for $P d x 1$ are reported to develop normally $[12,13]$, but become diabetic with age due to decreased beta cell function [37, 38] and increased beta cell apoptosis $[39,40]$. Future studies will determine whether these results are valid in vivo or merely reflect an artefact of the in vitro system.

A block in islet and enteroendocrine cell differentiation has been linked to NEUROG 3 mutations, but the human loss-offunction phenotype is variable, especially in its pancreatic endocrine aspects. In 2006, three individuals were described with NEUROG3 mutations giving rise to congenital malabsorptive diarrhoea with intestinal enteroendocrine cells. Unexpectedly, these individuals did not have permanent neonatal diabetes mellitus, despite their severe NEUROG3 mutations, suggesting that an unidentified factor compensated for the lack of functional NEUROG3 in the human pancreas [41]. This hypothesis was challenged by a study reporting that the mutations in these individuals were not null but hypomorphic [42] and, more recently, biallelic null mutations in NEUROG3 were discovered in an individual with permanent neonatal diabetes mellitus and intestinal anendocrinosis [43]. Subsequently, using a knockdown approach in hPSC- 
directed differentiation, as little as $10 \%$ NEUROG 3 was demonstrated to be sufficient for pancreatic endocrine cell differentiation [44]. Reconciliation in the field, however, was short lived as, more recently, two individuals with biallelic functionally null variants of the NEUROG3 gene without permanent neonatal diabetes mellitus were reported [45]. The reason for the difference in pancreatic function between the NEUROG3 null phenotype in human and mice remains poorly understood but may lie in subtle differences in the way NEUROG3 induces cell cycle arrest in pancreatic progenitors prior to endocrine differentiation [46].

Similarly, mutations in RFX6 also block endocrine differentiation and are associated with permanent neonatal diabetes mellitus, pancreatic hypoplasia, intestinal atresia and gallbladder aplasia or hypoplasia [15, 47]. These phenotypic differences compared with NEUROG3 deficiency are attributed to earlier expression of RFX6 in the early gut endoderm [15]. Enteric anendocrinosis, as documented in the case of NEUROG3 loss, has not been studied in detail for RFX6 loss in humans [48]. When RFX6 was deleted in hPSCs it decreased the efficiency with which pancreatic progenitors were generated from hPSCs [18], which is in line with the reduced size of the pancreas in some of the $R f x 6$-deficient mice and in people with biallelic RFX6 mutations [15, 49]. Apart from its role in pancreas development, RFX6 is important for the functioning of adult beta cells. In the human beta cell line EndoC- $\beta \mathrm{H} 2$, RFX6 regulates insulin gene (INS) transcription, insulin content and secretion and its knockdown decreased the activity of $\mathrm{Ca}^{2+}$ channels important for insulin exocytosis [21]. Mouse studies that established a regulatory role for RFX6 in islet development [50] have also shown that RFX6 is essential for maintaining the functional identity of adult beta cells, as it suppresses disallowed genes such as $L d h a$, Slc16a1, Pdgfra and Igfbp4 [48]. This effect on beta cell function has also been found in humans, as heterozygous truncating variants of RFX6 were found to cause a form of maturity-onset diabetes of the young (MODY) with reduced penetrance [51].

\section{Conclusions}

Pancreas development is regulated by hierarchical gene regulatory networks in which some transcription factors implicated in the pathology of permanent neonatal diabetes mellitus are key players. While many developmental steps are similar in mice and humans, there are intriguing differences, some of which we have highlighted. It is important to note that most of what we know about mammalian pancreas development stems from mouse genetics. The study of human pancreas development has benefited from mouse data, but also from model systems such as directed differentiation of hPSCs and human beta cell lines. Modelling human disease or development, however, is still modelling; while clinical cases of neonatal diabetes provide us with direct evidence of the impact of mutations in transcription factors, albeit often only evidence of the outcome and not of the process we are trying to understand. Finding a genetic cause for most forms of neonatal diabetes is currently feasible, but the genetics of some syndromic forms remain unclear and are thus a challenge for the future. The recent report of a mutation in the transcription regulator $C N O T 1$ as a cause of pancreas and gallbladder agenesis [52,53], a regulator that had not been previously identified as important for mouse pancreas development, shows that the natural model of human disease still has interesting insights to offer $[54,55]$. The scientific progress in our understanding of neonatal diabetes has increased our understanding of more common forms of diabetes, but hopefully they too will benefit from therapeutic advances. In the past, transcription factors were not considered targets for drug development, but the increased understanding of diseases and transcriptional regulation is enabling the development of such therapeutic strategies in other diseases [56]. We cannot expect such strategies to be useful for people with early and severe developmental defects, such as complete pancreas agenesis, but they may be able to target less severe forms of neonatal diabetes with mainly terminal differentiation defects. Neonatal diabetes already has success stories, but we are keen to add new ones to the good track record.

Funding REJ is a University of Manchester Presidential Fellow, and was previously supported by a Medical Research Council clinical research training fellowship in addition to support from the Academy of Medical Sciences. WS is supported by a postdoctoral grant from Agence Nationale de la Recherche (Laboratoire d'Excellence Revive, Investissement d'Avenir; ANR-10-LABX-73). The RS laboratory received funding from Agence Nationale de la Recherche (ANR BromoBeta), the Innovative Medicines Initiative 2 Joint Undertaking Rhapsody, under grant agreement no. 115881, supported by the European Union's Horizon 2020 research and innovation programme, European Federation of Pharmaceutical Industries and Associations (EFPIA) and the Swiss State Secretariat for Education, Research and Innovation (SERI) under contract number 16.0097, resources of which are composed of a financial contribution from the European Union's Seventh Framework Programme (FP7/2007-2013); the Innovative Medicines Initiative 2 Joint Undertaking under grant agreement no. 115797 INNODIA. This Joint Undertaking receives support from the European Union's Horizon 2020 research and innovation programme and EFPIA, JDRF International and The Leona M. and Harry B. Helmsley Charitable Trust; Fondation Bettencourt Schueller; the Laboratoire d'Excellence consortium Revive; Fondation pour la Recherche Médicale (EQU201903007793) and Fondation Francophone pour la Recherche sur le Diabete (FFRD).

Authors' relationships and activities RS is a shareholder in and consultant for Univercell-Biosolutions. WS and REJ declare that they have no relationships or activities that might bias, or be perceived to bias, their work.

Contribution statement All authors were responsible for drafting the article and revising it critically for important intellectual content. All authors approved the version to be published.

Open Access This article is licensed under a Creative Commons Attribution 4.0 International License, which permits use, sharing, 
adaptation, distribution and reproduction in any medium or format, as long as you give appropriate credit to the original author(s) and the source, provide a link to the Creative Commons licence, and indicate if changes were made. The images or other third party material in this article are included in the article's Creative Commons licence, unless indicated otherwise in a credit line to the material. If material is not included in the article's Creative Commons licence and your intended use is not permitted by statutory regulation or exceeds the permitted use, you will need to obtain permission directly from the copyright holder. To view a copy of this licence, visit http://creativecommons.org/licenses/by/4.0/.

\section{References}

1. Jennings RE, Berry AA, Kirkwood-Wilson R et al (2013) Development of the human pancreas from foregut to endocrine commitment. Diabetes 62(10):3514-3522. https://doi.org/10. 2337/db12-1479

2. Pan FC, Wright C (2011) Pancreas organogenesis: from bud to plexus to gland. Dev Dyn 240(3):530-565. https://doi.org/10. $1002 /$ dvdy. 22584

3. Salisbury RJ, Blaylock J, Berry AA et al (2014) The window period of NEUROGENIN3 during human gestation. Islets 6(3):e954436. https://doi.org/10.4161/19382014.2014.954436

4. Capito C, Simon MT, Aiello V et al (2013) Mouse muscle as an ectopic permissive site for human pancreatic development. Diabetes 62(10):3479-3487. https://doi.org/10.2337/db13-0554

5. Gradwohl G, Dierich A, LeMeur M, Guillemot F (2000) Neurogenin 3 is required for the development of the four endocrine cell lineages of the pancreas. Proc Natl Acad Sci U S A 97(4): 1607-1611. https://doi.org/10.1073/pnas.97.4.1607

6. Cano DA, Soria B, Martín F, Rojas A (2014) Transcriptional control of mammalian pancreas organogenesis. Cell Mol Life Sci 71(13):2383-2402. https://doi.org/10.1007/s00018-013-1510-2

7. Jeon J, Correa-Medina M, Ricordi C, Edlund H, Diez JA (2009) Endocrine cell clustering during human pancreas development. J Histochem Cytochem 57(9):811-824. https://doi.org/10.1369/jhc. 2009.953307

8. Hang Y, Stein R (2011) MafA and MafB activity in pancreatic $\beta$ cells. Trends Endocrinol Metab 22(9):364-373. https://doi.org/10. 1016/j.tem.2011.05.003

9. Arda HE, Li L, Tsai J et al (2016) Age-dependent pancreatic gene regulation reveals mechanisms governing human $\beta$ cell function. Cell Metab 23(5):909-920. https://doi.org/10.1016/j.cmet.2016.04. 002

10. Cyphert HA, Walker EM, Hang Y et al (2019) Examining how the MAFB transcription factor affects islet $\beta$-cell function postnatally. Diabetes 68(2):337-348. https://doi.org/10.2337/db18-0903

11. Jennings RE, Berry AA, Strutt JP, Gerrard DT, Hanley NA (2015) Human pancreas development. Development 142(18):3126-3137. https://doi.org/10.1242/dev.120063

12. Jonsson J, Carlsson L, Edlund T, Edlund H (1994) Insulinpromoter-factor 1 is required for pancreas development in mice. Nature 371(6498):606-609. https://doi.org/10.1038/371606a0

13. Offield MF, Jetton TL, Labosky PA et al (1996) PDX-1 is required for pancreatic outgrowth and differentiation of the rostral duodenum. Development 122(3):983-995

14. Ahlgren U, Jonsson J, Edlund H (1996) The morphogenesis of the pancreatic mesenchyme is uncoupled from that of the pancreatic epithelium in IPF1/PDX1-deficient mice. Development 122(5): $1409-1416$
15. Smith SB, Qu HQ, Taleb N et al (2010) Rfx6 directs islet formation and insulin production in mice and humans. Nature 463(7282): 775-780. https://doi.org/10.1038/nature08748

16. Gaertner B, Carrano AC, Sander M (2019) Human stem cell models: lessons for pancreatic development and disease. Genes Dev 33(21-22):1475-1490. https://doi.org/10.1101/gad.331397. 119

17. Balboa D, Saarimaki-Vire J, Borshagovski D et al (2018) Insulin mutations impair beta-cell development in a patient-derived iPSC model of neonatal diabetes. Elife 7:e38519. https://doi.org/10.7554/ eLife.38519

18. Zhu Z, Li QV, Lee K et al (2016) Genome editing of lineage determinants in human pluripotent stem cells reveals mechanisms of pancreatic development and diabetes. Cell Stem Cell 18(6):755768. https://doi.org/10.1016/j.stem.2016.03.015

19. Zeng H, Guo M, Zhou T et al (2016) An isogenic human ESC platform for functional evaluation of genome-wide-associationstudy-identified diabetes genes and drug discovery. Cell Stem Cell 19(3):326-340. https://doi.org/10.1016/j.stem.2016.07.002

20. Velayos T, Martinez R, Alonso $M$ et al (2017) An activating mutation in STAT3 results in neonatal diabetes through reduced insulin synthesis. Diabetes 66(4):1022-1029. https://doi.org/10.2337/ db16-0867

21. Chandra V, Albagli-Curiel O, Hastoy B et al (2014) RFX6 regulates insulin secretion by modulating $\mathrm{Ca}^{2+}$ homeostasis in human beta cells. Cell Rep 9(6):2206-2218. https://doi.org/10.1016/j.celrep. 2014.11.010

22. Lancaster MA, Knoblich JA (2014) Organogenesis in a dish: modeling development and disease using organoid technologies. Science 345(6194):1247125. https://doi.org/10.1126/science. 1247125

23. Huch M, Koo BK (2015) Modeling mouse and human development using organoid cultures. Development 142(18):3113-3125. https://doi.org/10.1242/dev.118570

24. Greggio C, De Franceschi F, Figueiredo-Larsen M et al (2013) Artificial three-dimensional niches deconstruct pancreas development in vitro. Development 140(21):4452-4462. https://doi.org/10. 1242/dev.096628

25. Huch M, Bonfanti P, Boj SF et al (2013) Unlimited in vitro expansion of adult bi-potent pancreas progenitors through the $\mathrm{Lgr} 5 / \mathrm{R}$ spondin axis. EMBO J 32(20):2708-2721. https://doi.org/10. 1038/emboj.2013.204

26. Loomans CJM, Williams Giuliani N, Balak J et al (2018) Expansion of adult human pancreatic tissue yields organoids harboring progenitor cells with endocrine differentiation potential. Stem Cell Rep 10(3):712-724. https://doi.org/10.1016/j.stemcr. 2018.02.005

27. Bonfanti P, Nobecourt E, Oshima M et al (2015) Ex vivo expansion and differentiation of human and mouse fetal pancreatic progenitors are modulated by epidermal growth factor. Stem Cells Dev 24(15): 1766-1778. https://doi.org/10.1089/scd.2014.0550

28. Aguilar-Bryan L, Bryan J (2008) Neonatal diabetes mellitus. Endocr Rev 29(3):265-291. https://doi.org/10.1210/er.2007-0029

29. von Muhlendahl KE, Herkenhoff H (1995) Long-term course of neonatal diabetes. N Engl J Med 333(11):704-708. https://doi. org/10.1056/NEJM199509143331105

30. Diabetes Genes. Targeted next generation sequencing. Available from www.diabetesgenes.org/tests-for-diabetes-subtypes/targetednext-generation-sequencing-analysis-of-45-monogenic-diabetesgenes/. Accessed 31 Jan 2020

31. Stoffers DA, Zinkin NT, Stanojevic V, Clarke WL, Habener JF (1997) Pancreatic agenesis attributable to a single nucleotide deletion in the human IPF1 gene coding sequence. Nat Genet 15(1): 106-110. https://doi.org/10.1038/ng0197-106

32. Schwitzgebel VM, Mamin A, Brun T et al (2003) Agenesis of human pancreas due to decreased half-life of insulin promoter 
factor 1. J Clin Endocrinol Metab 88(9):4398-4406. https://doi.org/ 10.1210/jc.2003-030046

33. Thomas IH, Saini NK, Adhikari A et al (2009) Neonatal diabetes mellitus with pancreatic agenesis in an infant with homozygous IPF-1 Pro63fsX60 mutation. Pediatr Diabetes 10(7):492-496. https://doi.org/10.1111/j.1399-5448.2009.00526.x

34. De Franco E, Shaw-Smith C, Flanagan SE et al (2013) Biallelic PDX1 (insulin promoter factor 1) mutations causing neonatal diabetes without exocrine pancreatic insufficiency. Diabet Med 30(5): e197-e200. https://doi.org/10.1111/dme.12122

35. Nicolino M, Claiborn KC, Senee V, Boland A, Stoffers DA, Julier C (2010) A novel hypomorphic PDX1 mutation responsible for permanent neonatal diabetes with subclinical exocrine deficiency. Diabetes 59(3):733-740. https://doi.org/10.2337/db09-1284

36. Wang X, Sterr M, Ansarullah et al (2019) Point mutations in the PDX1 transactivation domain impair human beta-cell development and function. Mol Metab 24:80-97. https://doi.org/10.1016/j. molmet.2019.03.006

37. Brissova M, Blaha M, Spear C et al (2005) Reduced PDX-1 expression impairs islet response to insulin resistance and worsens glucose homeostasis. Am J Physiol Endocrinol Metab 288(4):E707-E714. https://doi.org/10.1152/ajpendo.00252.2004

38. Brissova M, Shiota M, Nicholson WE et al (2002) Reduction in pancreatic transcription factor PDX-1 impairs glucose-stimulated insulin secretion. J Biol Chem 277(13):11225-11232. https://doi. org/10.1074/jbc.M111272200

39. Ahlgren U, Jonsson J, Jonsson L, Simu K, Edlund H (1998) $\beta$-Cellspecific inactivation of the mouse Ipfl/PdxI gene results in loss of the $\beta$-cell phenotype and maturity onset diabetes. Genes Dev 12(12):1763-1768. https://doi.org/10.1101/gad.12.12.1763

40. Johnson JD, Bernal-Mizrachi E, Alejandro EU et al (2006) Insulin protects islets from apoptosis via Pdx1 and specific changes in the human islet proteome. Proc Natl Acad Sci U S A 103(51):1957519580. https://doi.org/10.1073/pnas.0604208103

41. Wang J, Cortina G, Wu SV et al (2006) Mutant neurogenin-3 in congenital malabsorptive diarrhea. N Engl J Med 355(3):270-280. https://doi.org/10.1056/NEJMoa054288

42. Jensen JN, Rosenberg LC, Hecksher-Sorensen J, Serup P (2007) Mutant neurogenin-3 in congenital malabsorptive diarrhea. N Engl J Med 356(17):1781-1782. https://doi.org/10.1056/NEJMc063247

43. Rubio-Cabezas O, Jensen JN, Hodgson MI et al (2011) Permanent neonatal diabetes and enteric anendocrinosis associated with biallelic mutations in NEUROG3. Diabetes 60(4):1349-1353. https://doi.org/10.2337/db10-1008

44. McGrath PS, Watson CL, Ingram C, Helmrath MA, Wells JM (2015) The basic helix-loop-helix transcription factor NEUROG3 is required for development of the human endocrine pancreas. Diabetes 64(7):2497-2505. https://doi.org/10.2337/db14-1412

45. Solorzano-Vargas RS, Bjerknes M, Wang J et al (2020) Null mutations of NEUROG3 are associated with delayed-onset diabetes mellitus. JCI Insight 5:127657
46. Solorzano-Vargas RS, Bjerknes M, Wu SV et al (2019) The cellular regulators PTEN and BMI1 help mediate NEUROGENIN-3induced cell cycle arrest. J Biol Chem 294(41):15182-15192. https://doi.org/10.1074/jbc.RA119.008926

47. Mitchell J, Punthakee Z, Lo B et al (2004) Neonatal diabetes, with hypoplastic pancreas, intestinal atresia and gall bladder hypoplasia: search for the aetiology of a new autosomal recessive syndrome. Diabetologia 47(12):2160-2167. https://doi.org/10.1007/s00125004-1576-3

48. Piccand J, Strasser P, Hodson DJ et al (2014) Rfx6 maintains the functional identity of adult pancreatic beta cells. Cell Rep 9(6): 2219-2232. https://doi.org/10.1016/j.celrep.2014.11.033

49. Concepcion JP, Reh CS, Daniels M et al (2014) Neonatal diabetes, gallbladder agenesis, duodenal atresia, and intestinal malrotation caused by a novel homozygous mutation in RFX6. Pediatr Diabetes 15(1):67-72. https://doi.org/10.1111/pedi.12063

50. Soyer J, Flasse L, Raffelsberger W et al (2010) Rfx6 is an Ngn3dependent winged helix transcription factor required for pancreatic islet cell development. Development 137(2):203-212. https://doi. org/10.1242/dev.041673

51. Patel KA, Kettunen J, Laakso M et al (2017) Heterozygous RFX6 protein truncating variants are associated with MODY with reduced penetrance. Nat Commun 8(1):888. https://doi.org/10.1038/ s41467-017-00895-9

52. Hilbrands R, Keymolen K, Michotte A et al (2017) Pancreas and gallbladder agenesis in a newborn with semilobar holoprosencephaly, a case report. BMC Med Genet 18(1):57. https://doi.org/10.1186/s12881-017-0419-2

53. De Franco E, Watson RA, Weninger WJ et al (2019) A specific CNOT1 mutation results in a novel syndrome of pancreatic agenesis and holoprosencephaly through impaired pancreatic and neurological development. Am J Hum Genet 104(5):985-989. https:// doi.org/10.1016/j.ajhg.2019.03.018

54. Shield JP (2007) Neonatal diabetes: how research unravelling the genetic puzzle has both widened our understanding of pancreatic development whilst improving children's quality of life. Horm Res 67(2):77-83. https://doi.org/10.1159/000096354

55. Sperling MA (2005) Neonatal diabetes mellitus: from understudy to center stage. Curr Opin Pediatr 17(4):512-518. https://doi.org/10. 1097/01.mop.0000170517.20025.51

56. Li S, Vallet S, Sacco A, Roccaro A, Lentzsch S, Podar K (2019) Targeting transcription factors in multiple myeloma: evolving therapeutic strategies. Expert Opin Investig Drugs 28(5):445-462. https://doi.org/10.1080/13543784.2019.1605354

Publisher's note Springer Nature remains neutral with regard to jurisdictional claims in published maps and institutional affiliations. 